\title{
FRANCISCO AYALA, ESCRITOR DE NOVELAS CORTAS: REVALORIZACIÓN Y RECONTEXTUALIZACIÓN DE EL RAPTO
}

\author{
Carmen M. ${ }^{\text {a }}$ Pujante Segura \\ Universidad de Murcia \\ carmenpujante@um.es
}

Resumen: En este trabajo se pretenden iluminar algunos aspectos de El rapto, novela corta de Francisco Ayala que, como toda la obra del escritor, ha sido objeto de profundo estudio por parte de destacados especialistas. Aquí se busca poner en valor, no solo la faceta de Ayala como cultivador del género de la novela corta, sino también la relevancia de esa obra, que inauguraba la que sería la última de las colecciones de novelas cortas, La Novela Popular Española. Ahí se publicó suelta en el año 1965, una fecha clave en la vida de su autor, que en el momento de su escritura aún se encontraba en el exilio. Aparte de por sus cualidades técnicas, temáticas o formales, especialmente por cuanto se trata de una fabulosa recreación cervantina, parece necesario desentrañar el contexto histórico-literario, editorial y también personal de la publicación de El rapto. Para ello también se han de revalorizar los documentos disponibles de la censura así como las cartas y las apreciaciones del autor mismo sobre esta obra.

Palabras clave: Francisco Ayala, novela corta, El rapto, La Novela Popular Española, exilio.

\section{FRANCISCO AYALA, NOUVELLE WRITER: REVALUATION AND RECONTEXTUALIZATION OF EL RAPTO}

\begin{abstract}
This article aims to highlight some aspects of El rapto, Francisco Ayala's short novel that, like all the work of this writer, has been analyzed in depth by prominent scholars. Here we seek to value, not only the facet of Ayala as a writer of the genre of the short novel, but also the relevance of that work, which inaugurated La Novela Popular Española, the last of the collections of short novels. It was published in 1965, a key date in the life of its author, who at the time of his writing was still in exile. Apart from its technical, thematic or formal qualities, especially as a fabulous recreation of Cervantes, it seems necessary to unravel the historical, sociological, editorial and personal context of the publication of El rapto. It is also necessary to revalue the available documents of the censorship, as well as the letters and other appreciations about this work of Francisco Ayala.
\end{abstract}

Keywords: Francisco Ayala, nouvelle, El rapto, La Novela Popular Española, exile.

DOI: $\underline{\text { https://doi.org/10.24029/lejana.2018.11.257 }}$ 
Recibido: el 31 de mayo de 2018

Aceptado: el 30 de agosto de 2018

Publicado: el 22 de octubre de 2018 


\section{Introducción}

El rapto de Francisco Ayala no deja hoy de interpelarnos, aun cuando se trata de una novela corta ya analizada por parte de destacados estudiosos de este "escritor universal", como es reconocido en el volumen que en homenaje al autor coordinaron Sánchez Trigueros y Vázquez-Medel (2001). Baste citar algunos de los trabajos sobre El rapto censados en la excelente página electrónica de la Fundación Francisco Ayala, como los de Sánchez (1966), García Montoro (1968), Ellis (1969), Gruia (2011) o Pozuelo Yvancos (2015), aparte de estudios más generales como los ofrecidos por Richmond, Irizarry, Baquero Goyanes y Chicharro Chamorro, entre tantos otros que han actualizado los incluidos en la bibliografía ofrecida por Amorós ya en el año 1989. Partiendo de tales meritorias aportaciones, pretendemos poner el foco en algunos recodos de esa obra ayaliana que, a nuestro parecer, no han sido suficientemente resaltados o valorados: sin dejar de asumir los estudios anteriores, enfocados desde una perspectiva más formal o intertextual pero en ningún momento agotados, se quiere aquí subrayar la relevancia de esa obra en el contexto histórico-literario, editorial y personal de su publicación. Así, se busca poner énfasis en una obra escrita en el exilio, pero revisada (por el editor de la colección y por la censura del Estado) para ser publicada en España, el país al que su autor pronto iba a poder regresar de manera definitiva. Quizá con esta novela corta estaba preparando su regreso, un regreso para el que no podía no recrear algunas obras cervantinas. Se estudiará, pues, la enmarcación de El rapto dentro de una colección de novelas cortas, del exilio de parte de la literatura española, de la España de los años sesenta, de la censura de la dictadura franquista y de la propia experiencia del escritor.

El caso de Francisco Ayala resulta atrayente y paradójico por cuanto estaríamos ante uno de los escritores más "canónicos" dentro de una suerte de lista de autores españoles de novelas cortas en el siglo XX, un género que, como se sabe, de alguna manera ha permanecido relegado por la crítica literaria. Además de sociólogo, profesor y traductor, Ayala fue un gran cultivador de la narración, alternando diferentes subgéneros; por ejemplo, un gran número de relatos breves suyos era antes publicado en prensa o revistas, un "hábitat natural" para las narraciones cortas desde el siglo XIX. Tras unas primeras tentativas novelísticas ineludiblemente cervantinas-, Ayala se iniciaba con relatos breves y lo hacía además en plena época vanguardista con El boxeador y un ángel en 1929 y Cazador en el alba en 1930. Continuó cultivando la narrativa breve durante el exilio americano, incluso tras un período de "sequía ficcional"; de hecho, de esa época son Los usurpadores y La cabeza del cordero, compilaciones de narraciones breves publicadas en 1949, año en que el escritor preparaba su traslado a Puerto Rico desde Argentina. Existen referencias explícitas del autor a las novelas cortas de La cabeza del cordero, entre otras alusiones que se verán más adelante que retratarán la faceta de crítico y crítico de la crítica que también tuvo Francisco Ayala, quien tan magistralmente supo alternar la teoría con la práctica literaria (Chicharro Chamorro, 1992).

Con narraciones cortas también regresaría - literariamente - a su país natal gracias a una discreta publicación en la Revista de Occidente, en concreto, la de Historia de macacos en 1955. Diez años más tarde publicaba en España gracias a La Novela Popular la obra titulada finalmente El rapto, dándola a la imprenta tras algunos —interesantes - reajustes que también se verán a continuación. Otros tantos relatos también verían la luz en España, especialmente a través de revistas como Papeles de Son Armadans o Ínsula a partir de los 
años sesenta, esperando el regreso que llegaría tras algunas esporádicas visitas en 1976, apenas finalizada la dictadura. Se ha de destacar, pues, su familiaridad con el mundo de las revistas intelectuales y literarias, ya que durante el exilio se movía por ese mundo editorial, por ejemplo, colaborando en la revista Sur o llegando a fundar la revista Realidad junto con Lorenzo Luzuriaga. También algunas de sus novelas cortas fueron publicadas "sueltas" en medios afines, aunque estuvieran destinadas a ser recogidas posteriormente dentro de un recueil, como también va a ocurrir con El rapto. Fue publicada en 1965 en esa colección, que editaba precisamente Alfaguara, editorial tras la cual se encontraba Jorge Cela, hermano de Camilo José Cela, escritor con el que Francisco Ayala en los meses previos a la publicación de El rapto mantuvo correspondencia, a la que se accederá más adelante en este trabajo.

Aquí seguiremos la edición original de la obra, que solo un año más tarde era incluida en una recopilación titulada De raptos, violaciones y otras inconveniencias, nuevamente a cargo de Alfaguara, pues se trataba de obtener mayor rédito de la publicación así como de evitar el olvido o la pérdida de la obra. No obstante, también en 1974 fue recopilada bajo el título de El rapto. Fragancia de jazmines. Diálogo entre el amor y un viejo, en una edición a cargo de la estudiosa Estelle Irizarry. A estas ediciones otras les han seguido, pues, de hecho, el avatar de las diferentes publicaciones y reordenaciones, aun en la unidad de la obra toda de Ayala, bien merece un estudio (que, nos consta, está en ciernes).

\section{Recontextualización de la novela corta de El rapto: del exilio a España}

No se debe pasar por alto el contexto editorial en el que la novela corta de El rapto ve la luz, aunque indudablemente trascienda el medio y la historia gracias a sus cualidades intrínsecas. Resulta decidor y significativo — no sabemos si hasta provocador e intencionado- que fuera el relato con el que se decidiese inaugurar la colección de La Novela Popular Española, la última de la estirpe de El Cuento Semanal y, ciertamente, una de las más olvidadas. ${ }^{1}$ Esta colección vendría a demostrar que ese medio editorial seguía vivo durante el franquismo, permitiendo publicar desde los circuitos literarios populares que, entre otras aportaciones,

\footnotetext{
${ }^{1}$ El mundo de las colecciones de novelas cortas ha sido estudiado en su apogeo desde 1907 (Magnien et al., 1986) hasta 1936 (Martínez Arnaldos, 1975), pero falta información sobre ese mundo editorial en el exilio. No obstante, en la Bibliografía e historia de las colecciones literarias en España de Alberto Sánchez Álvarez-Insúa, que abarca el período que va de 1907 a 1957 (por lo que no cubriría todo el período de la dictadura), se registran datos escasos pero interesantes sobre la vida de las colecciones en el exilio. En su estudio, Casas (2007) profundiza en el relato breve dentro del periodo comprendido entre 1948 y 1969, en el que tuvo tanta relevancia la prensa (aunque no abarque explícitamente la novela corta). Hay estudios que se han centrado en otros géneros cultivados en el exilio, como la poesía (Ramos Ortega, 2010), refiriéndose también a la importancia del mundo de las revistas; por ejemplo, el estudio de Caudet (1992) se centra en las revistas del exilio en México, entre las que destaca Las Dos Españas, la revista de Arana y Andújar, en la que existía una sección para poemas y otra para el cuento del mes (pero no para la novela corta, género que sí cultivarían sus dos promotores). Pero se ha destacar el Diccionario biobliográfico: de los escritores, editores y revistas del exilio republicano de 1939, editado por Manuel Aznar en 2016. Ante tal necesidad crítica, la revista Quimera dedicaba un monográfico del año 2005 a "La narrativa breve del exilio republicano", erigiéndose como uno de los estudios elementales y encabezando una labor de rescate y estudio, aunque dedique una atención mayor al cuento (más allá de las oscilaciones terminológicas presentes) y a determinados autores como Aub, Ayala, Dieste, Barea, Sender, Masip, Andújar y Conte, en detrimento de la novela corta y de otros escritores. Destacaremos el estudio de Pérez Bowie, que traza una evolución de la narrativa breve y destaca los años 60 como aquéllos en los que se inicia el regreso escalonado de escritores a España y las primeras publicaciones de relatos escritos en el exilio (sin tratar la guerra civil pero sí con una actitud autocrítica), como es el caso de Ayala.
} 
garantizaban cierta popularidad y cierto apoyo económico. Con el nombre de La Novela Popular (Contemporánea. Inédita. Española), la colección publicó con periodicidad quincenal hasta sesenta y seis números entre los años 1965 y 1967. Dependía de la editorial Alfaguara y fue dirigida por Jorge Cela Trulock. Con su formato de 16x11 cm, recuerda al formato de las tiradas de anteriores colecciones de novelas cortas. Ese número alcanza las 84 páginas, sumando 28 líneas por página (con una media de 9 palabras por línea). El número primero no cuenta con ninguna imagen en la portada sino con rayas horizontales llamativamente rosas, pues hasta más adelante no se incluiría un diseño en ella. Aun en la sencillez y humildad de este tipo de publicaciones, se trata de una edición cuidada que favorece una lectura ágil. Esta colección merecería un estudio particular y poliédrico, iniciado por Lozano Marco (2003) en un valioso artículo que, no obstante, se centra en el relato de A. Zamora Vicente en esa colección.

Entre la variada nómina de autores y de obras que censa Lozano Marco — estudioso también del género de la novela corta-, predominan los escritores de una edad aproximada de treinta años: "los que eran niños en la guerra, los nacidos entre 1925 y 1936, conocidos como la «generación del medio siglo»" (2003: 112). Encontramos a exiliados como Manuel Andújar, Eugenio Granell o Francisco Ayala (todos estos, por cierto, cultivadores de la novela corta). ${ }^{2}$ A falta de un estudio exclusivo sobre esta interesante colección, es de justicia valorar el hecho de haber servido de plataforma editorial para escritores noveles, pero también para algunos que buscaban regresar del exilio, aunque en un principio paradójicamente solo pudiera ser posible gracias a sus textos: podría ser el caso de Ayala, que en los años sesenta ya era un escritor con una rica trayectoria que incluía novelas cortas.

La Fundación Francisco Ayala le dedica una sección exclusiva a El rapto, incluyendo referencias del propio autor sobre su obra. Poco después de su publicación, en las páginas de "Nueva divagación sobre la novela", de 1967, Ayala se refería a la "incitación de Camilo José Cela" a la hora de redactar ese texto, por lo que se podría considerar una obra "por encargo". Admite que el destino era una "serie popular", pero que esa casa editorial, la de Alfaguara,

\footnotetext{
${ }^{2}$ En un estudio sobre la novela corta española en el exilio (Pujante Segura, 2018; en prensa) componemos un corpus —irremediablemente provisional - que incluiría a Cecilia G. de Guilarte, José Ramón Arana, Ramón J. Sender, Manuel Andújar, Eugenio F. Granell, Paulino Masip, Segundo Serrano Poncela, Juan Espinasa y, claro, Francisco Ayala, aun siendo él uno de los que cuestionara tal etiqueta en un célebre artículo y aun pudiéndose tratar del autor más "canónico" dentro de esta suerte de rescate de escritores de novela corta. En líneas generales, los escritores de novelas cortas en el exilio destacan por su trayectoria polifacética, también dentro del ámbito literario gracias al cultivo de diferentes géneros, incluidos los narrativos. A modo de muestra y para gozar de una mayor perspectiva, sería conveniente hacer alguna mención a otros autores. Por ejemplo, Manuel Andújar también "volvería" a España con una novela corta, La sombra del madero: firmada en junio de 1965 en México y publicada en el año 1966 en La Novela Popular (en el número 38, en un volumen que supera las cien páginas), es una obra rescatada bajo el título de Narraciones en 1989, junto con Las ilusiones subversivas por la Editorial Universidad de Sevilla. Al margen de la delimitación por generaciones, algunos de los escritores españoles exiliados cultivaron la novela corta antes de marcharse de España, pero la mayoría optó por él de manera excepcional durante su exilio, incluso para publicar en su país; así, en ese estudio consideramos la novela corta como un género tentativo a la par que intenso en su concentración narrativa y argumentativa, además de un género "discreto" si, además, se considera su habitual forma de publicación. Aparte de estos narradores del exilio, en un panorama general de la narrativa española de posguerra están Camilo José Cela y Gonzalo Torrente Ballester, escritores canónicos (como causa-consecuencia del período franquista) que, no obstante, también fueron cultivadores de la novela corta, especialmente dentro del círculo editorial de las colecciones de novelas cortas y de las posteriores compilaciones. De hecho, muchos de los escritores españoles, como Carmen Laforet, Elisabeth Mulder o el mencionado Camilo José Cela, publicaron en una de las últimas colecciones de novelas cortas, La Novela del Sábado (Pujante Segura, 2010).
} 
también se había encargado recientemente de su reedición en un tomo recopilatorio (destino habitual de los relatos breves o semibreves). Se refiere a ella como "novelita", en la que plasma un "argumento cervantino para regresar a la España de hoy" con el tema de unos obreros españoles que trabajan en Alemania y vuelven a su país por vacaciones. Creemos que ahí se encuentra una de las claves de este relato: en realidad, era Ayala quien deseaba volver a la España de ese momento pero, a falta de poder hacer realidad una presencia efectiva, llegaba la publicación literaria, y más tratándose de la recreación cervantina de un capítulo de $E l$ Quijote, e incluso de novelas — cortas - como la de El curioso impertinente o algunas de las Novelas ejemplares. ${ }^{3}$

En otro trabajo, titulado "Reflexiones sobre la estructura narrativa", de 1970, usa el término "novelita" para referirse a El rapto. Ahí se hace eco de algunos estudios que sobre la obra pronto han surgido, como es el de García Montoro (1968) a raíz del concepto de Barthes del fait divers. Ello viene a demostrar, por un lado, la oscilación terminológica que suele rodear el género de la novela corta, y por otro, la importante recepción crítica de esta obra. Dos años más tarde, en "Confrontaciones", el escritor vuelve a reflexionar sobre esa obra, en concreto sobre la multitud de alusiones literarias, si bien están presentes en toda la obra narrativa ayaliana (Hiriart, 1972). Tampoco negará la base de su experiencia personal plasmada en este y en otros relatos, como hace en "Regreso a Buenos Aires", dentro de Recuerdos y olvidos (Ayala, 1982: 354). Así pues, ese es el relato que decide publicar en su país, al que en calidad de turista ya había podido venir, como recordará en "Cervantes y yo" (Ayala, 2005: 1497).

Con todo, Francisco Ayala posee una lúcida consciencia ante los géneros literarios narrativos, incluido el de la novela corta, al que se refiere en ocasiones aunque no le dedique ninguna de sus reflexiones en particular. Sin embargo, como suele suceder con otros escritores y con otros estudiosos, Ayala también oscilará a la hora de escoger un término con el que referirse concretamente a esos relatos situados entre el cuento y la novela. Y es que, tal y como hace también Pozuelo Yvancos (2015) al referirse explícitamente a esta "novela corta", se basa en el cuento cervantino incluido en el capítulo LI de la primera parte del Quijote, relatado y enmarcado a su vez por Eugenio, el cabrero, que contará la historia de Vicente de la Roca, personaje rescatado para su obra por Ayala. El escritor tiene conciencia de que, como todo cuento, ya ha sido contado pero de otra manera: retomará su texto en el año 1993 en una "colección”, tal y como él la denomina, incluyendo un prólogo en el que reflexiona sobre el género del cuento, marcado por sus variantes en el modo de contar, no en el asunto contado.

\footnotetext{
3 Justamente en el estudio de Richmond titulado "Raíces de la (re)creación: reflejos del exilio en Los usurpadores" se da una clave que haríamos extensiva a El rapto: "Su primera recopilación de relatos tras la guerra civil es Los usurpadores, obra que es para él el primer paso en su búsqueda del tiempo perdido, esta vez mediante un regreso literario al pasado más o menos lejano de su país: una indagación histórica que, en cuanto espejo del presente, pretende a su vez iluminarlo" (2011: 18-19).
} 


\section{Revalorización de El rapto: novela corta, censura y cartas}

Entre los textos de Ayala que podrían ser considerados como novelas cortas, ${ }^{4}$ dejando aparte Los usurpadores (compilación de relatos publicada meses antes), salen a la luz los de $\mathrm{La}$ cabeza del cordero en Buenos Aires en 1949. Y es que La cabeza del cordero sería una recopilación de cuatro novelas cortas según el escritor en Mis páginas mejores, en concreto, en un fragmento que data del mismo año de El rapto:

Muy malo o muy bueno debe de ser este libro mío - La cabeza del cordero-, a juzgar por las dificultades de acceso a sus naturales lectores con que desde el principio mismo hubo de tropezar. Se compone de cuatro novelas cortas, unidas por el tema y preocupación básicos que, salvo la alusión a concretas circunstancias, no difiere de los que inspiran otras de mis prosas narrativas de igual época. La doctrina es la misma, aunque usa otros ejemplos; y esa doctrina tiene carácter moral, no intención política. (Ayala, 1965b: 14)

La oscilación en los términos atañe a esos relatos, igual que sucede con El rapto, editada inicialmente "suelta" o, en palabras de Blanes (2001), "independiente" o "intercambiable". Pero también se aprecia en estudios históricos de la literatura española del siglo XX, como es el Manual de literatura española de Pedraza y Rodríguez (1996), un manual que, no obstante, arroja luz sobre la novela corta aunque se refiera a la narración en general. Dentro del tomo consagrado a la "Posguerra: narradores" se reserva un importante espacio para los novelistas del exilio que comienza con Rosa Chacel y sigue con Ramón J. Sender, aunque no se alude a las novelas cortas que ese autor publicó "sueltas" en colecciones literarias como es El vado. Contrastaría Sender con el tratamiento del siguiente escritor, Francisco Ayala justamente, dentro de cuya obra se mencionan títulos de narraciones, pero no de manera explícita ninguna novela corta pues, por ejemplo, se habla de El rapto como de una "obrita". Huelga advertir que el uso de estos diminutivos no pocas veces induce a ambigüedad, pues podrían referirse a la extensión, la calidad o la importancia de la obra en cuestión.

Pero la ambigüedad también rodea a esta obra, igual que rodea a las Novelas ejemplares de Cervantes, a pesar de la máscara de la ejemplaridad. El juego de máscaras y laberintos de esas obras cervantinas era estudiado por Baquero Goyanes (1981 [1976]), quien también estudiaba conjuntamente el arte del relato breve de Cervantes y de Ayala (1977). Las conexiones con Cervantes son tantas que dan para un estudio como el de Escudero (1989). Esa supuesta ejemplaridad podría ampliar la reflexión a la situación de guerra y de exilio de tantos escritores españoles. El rapto arranca con un tradicional relato marco que tiene lugar en un viaje en tren, donde el narrador — que tanto se parece al escritor- charlará con

\footnotetext{
${ }^{4}$ A partir de las numerosas reflexiones de Francisco Ayala sobre la novela y sobre el cuento, J. R. Valles Calatrava ha estudiado las similitudes y las diferencias entre ambos géneros, aludiendo tangencialmente a la necesidad de hablar también de novela corta, a la que, no obstante, el escritor no le dedicó explícitamente una de sus reflexiones críticas: "Pero sin excluir los planteamientos sobre la organización discursiva o estructural más cerrada, iterativa y esquemática del cuento en general, la presencia no obstante del relato breve conocido como «cuento literario», más semejante en todos los aspectos a la novela que el folclórico y en muchas ocasiones menos esquemático y cerrado, puede hacer interesante revalorizar en otro sentido, apoyado en bases pragmáticas socioculturales, el criterio de longitud de la narración (cuya naturaleza reconoce pero entiende demasiado mecánica Ayala) como otra clave complementaria de deslinde entre novela y cuento, sobre todo si se piensa también en la «novela corta», distinguida incluso terminológicamente en española" (1992: 385). Para el relato breve tradicional, Ayala también se referiría a las simetrías formales o el esquematismo dirigido temáticamente al suceso y no tanto al personaje. De manera más general, otros estudios como el de Scholz (2013) han profundizado en las oscilaciones entre el cuento y la novela que parecen atañer al género de la novela corta.
} 
compañeros de vagón. Además del tradicional recurso del marco, Ayala rescata así el recurso epistolar incluyendo al final, en esa suerte de epílogo que es la carta de Vicente de la Roca a Manolo Tejera (Patricio en posteriores ediciones). Con la carta se producirá un giro a la consideración del tema de la lealtad de la mujer: la mujer en cuestión es Julita, la novia que Vicente arrebatará a Manolo, pero solo — supuestamente - por demostrarle la volatilidad de la mujer y, por ende, su amistad. Pero algo que comparte esta novela corta con las anteriores es el hecho de ser enmarcada en el ambiente de un pueblo de costumbres, aunque no por ello sus habitantes se dejen de percatar de la fanfarronería del que viene de fuera, Vicente, que volvía en moto a sus orígenes, pues era sobrino de quien llegara a ser alcalde allí en la República.

No obstante, la historia de El rapto es tan rica que podría leerse desde múltiples interpretaciones. Ya se ha aludido, como hace Carmen Escudero (1989), a la posible relación homosexual entre los dos hombres protagonistas, pero también se debería enfocar desde la tan traída ejemplaridad cervantina, un debate ya intrínseco al género literario de las novelas (cortas) en su concepción entre lo moral y lo estético, no exenta de una ironía que ha de ponerse en relación con el contexto socio-histórico de Miguel de Cervantes. El debate podría trasplantarse mutatis mutandi al contexto de la dictadura franquista por cuanto se hace efectiva la censura artística por parte del gobierno. Gracias a la página electrónica de la Fundación Francisco Ayala podemos disponer del expediente de la censura vertido sobre $E l$ rapto (este tipo de testimonios ya lo echábamos en falta en el estudio sobre la colección de La Novela del Sábado de los años cincuenta). Lo vemos con membrete del Ministerio de Información y Turismo (para el que llegó a trabajar Camilo J. Cela, que ha sido conocido como "el censurador censurado"), en particular en la Dirección General de Información, Sección de Orientación Bibliográfica (repárese en el nombre), con número de expediente 7511-64, fechada en diciembre del año $1964 .^{5}$

En el expediente ya se aprecia algo singular como es el título inicial de la obra, a saber, Vicente de la Roca. En la importancia del tratamiento de este personaje ya han reparado los estudios sobre El rapto, viendo en ello el corazón de la recreación ayaliana del modelo cervantino. Asimismo, en tal expediente consta el nombre de la colección como Novela Popular, en la cual aparecería el volumen, de unas 45 páginas según se hace saber, si bien llega a las 84, a las que se le han de sumar otras del final con información editorial (esto es, el doble, pues lo medirían por pliegos). Se preveía una tirada de 6000 ejemplares, un número

\footnotetext{
${ }^{5}$ Creemos que no podemos desaprovechar la ocasión para referirnos al que sería el octavo número de La Novela Popular Española, a saber, El paralelo 38 de Alfonso Sastre, rareza por cuanto se trata de una obra narrativa "experimental" de un reconocido autor dramático. La bibliografía de la edición de Los hombres y sus sombras en Antología Teatral Española fue la primera que preparó su estudioso, Mariano de Paco (1988). La fue recopilando, añadiendo para El paralelo 38 el dato de esa edición tal y como lo encontró: "La edición fue retirada por la censura antes de distribuirse". Pero para la edición del libro Alfonso Sastre, el propio autor se la supervisó, confirmando la información sobre la retirada por parte de la censura. Además, ese dato había aparecido en el número 30 de Suplementos Antropos dedicado a Alfonso (en enero de 1992), en cuya página 124 pone esta nota al texto de la obra, que se publica completa: "Impresa por «La novela popular» de Madrid en 1965 no llegó a distribuirse porque fue retirada por la censura. Motivo: a petición del editor se había ampliado el texto con unas páginas que no figuraban en el ejemplar enviado a censura". Hemos de agradecer toda esta información al profesor Mariano de Paco, si bien nuestros interrogantes siguen necesitando una respuesta: ¿entonces, cuál ha sido el curioso avatar de ese ejemplar de La Novela Popular para poder llegar hoy a nuestras manos en su versión original? Una vez más, ello serviría para reiterar el interés de un futurible estudio sobre esta colección popular en concreto.
} 
nada desdeñable que se corresponde con un dato de valor en los estudios sobre estas colecciones españolas de novelas cortas. Según consta, el autor no tiene antecedentes. Aparece firmado por el Jefe del Negociado, pero la firma es ilegible. Son interesantes las preguntas del cuestionario subsiguiente, a pesar de no ser respondidas (lo que entendemos como una respuesta negativa): “Ataca el dogma? ¿A la moral? ¿A la Iglesia o a sus Ministros? ¿Al régimen y a sus instituciones? ¿A las personas que colaboran o han colaborado con el Régimen? Los pasajes censurables ¿califican el contenido total de la obra?”. En otras observaciones se lee el que entenderían como argumento resumido de la obra:

Sobre la fea actuación de un emigrante español en Alemania que de regreso en nuestra nación y por motivos que no aparecen claros, logro [sic] desacreditar rotundamente a una ingenua muchacha que como la mejor del pueblo donde moraba, se disputaban los dos mozos de mayor partido del termino [sic]. Demostró que pudo conseguir de ella cuanto le pidió para despreciarlo y destruyó la fé [sic] que en ellas tenian [sic] los enamorados, al solo fin de demostrar que de ninguna mujer debe uno fiarse.

Se ha de contrastar con el siguiente expediente, donde se incluye un resumen diferente escrito a mano:

Vicente, trabajador español en Alemania, regresa a España y marcha al pueblo de sus antepasados. Es un tipo simpático, un gana voluntades. Entabla amistad con Manolo quien le presenta a Julita, por la que siente verdadero amor. Pasan los días y las semanas sin que nada ocurra, hasta que un domingo estalla la noticia. Vicente y Julita se habían escapado, llevándose ésta dinero y joyas. Aparece Julita en Figueras, sin deterioro físico, pero sin Vicente y sin dinero y joyas. Al pasar el tiempo, Manolo recibe carta de Vicente, pidiéndole perdón por la hazaña, pero haciéndole ver lo frágil que resulta ser su amor y proponiéndole que se vaya con él a trabajar.

PUEDE AUTORIZARSE con las tachaduras que figuran en las paginas [sic] 6,-7 y 8 [los números aparecen con tinta roja, frente a la azul del resto].

En el informe fechado un mes después se añade al pie que puede autorizarse la obra pero "suprimiendo lo señalado en las páginas 6, 7 y 8". No sabemos a cuáles correspondería, pero contando con los folios que ellos evaluaban, se trataría de las páginas 10 a 16 aproximadamente, esto es, al particular marco prologal de la obra. Finalmente obtiene la aprobación en febrero de 1965, de manera que poco después será publicado el relato, pero con el título de El rapto. De hecho, se ha de destacar que se añaden otros expedientes, a modo de apéndice, en los que escrito a bolígrafo se encuentra lo siguiente: "Cambio de título de oficio o/v. Jefe Sección”. En otra ficha incluida, escrita a máquina, aparece el título Vicente de la Roca, pero entre paréntesis, y escrito encima, sin paréntesis, El rapto. Finalmente encontramos la solicitud de autorización, firmada por el editor, esto es, Alfaguara, con la misma dirección que aparece en los créditos del número primero $-\mathrm{y}$ siguientes - de su colección La Novela Popular. Sí habrá cambio en el precio, pues en la solicitud de autorización, ya firmada por Fernando Huarte, aparece como precio previsto 15 pesetas, cuando sabemos por la portada que finalmente ese primer número se vende por 20 pesetas.

También son de gran valor las cartas que la Fundación Francisco Ayala proporciona con el epistolario (originales y transcritas, por lo que se ha de aprovechar para felicitar por tal iniciativa y cuidado). Podemos leer una carta de Ayala a Camilo José Cela, fechada en diciembre de 1964, esto es, prácticamente coetánea de esos expedientes de la censura. Aprovechando para felicitar la Navidad, en esa carta le envía el relato: "No dirás que no soy 
cumplidor: ahí va mi Vicente de la Roca. Ya me dirás lo que te parece"; pero añade en posdata: "Quisiera corregir las pruebas. Vale la pena, si ha de ser el primer cuaderno, que salga por completo limpio de erratas". Apreciamos el cuidado puesto, pero también la fragua de la escritura. Con todo, afortunadamente se dispone de una carta anterior, datada el $11 \mathrm{de}$ noviembre de 1964 en Nueva York, que merece ser reproducida por muchos motivos:

\section{Mi querido Camilo:}

He tardado en contestar a tu última carta porque tuve que ir a Méjico para tomar parte en una de esas reuniones internacionales que, si no salvan al mundo, por lo menos fomentan el turismo, y al regreso me la he encontrado esperando. En fin, te escribo.

Como ya te insinué en carta anterior, sin extenderme en detalles, estoy —o está la filial de Sudamericana- a vueltas con la censura (que sin perdón ni paliativos así hay que seguirla llamando) para que no ponga objeción a un volumen de mis novelas cortas donde se incluya "La cabeza del cordero", contra la cual parecía haberla. En fin, estamos jugando el bonito juego del ratón y el gato. Parece que, por no decir que cierran el paso a la tal indigesta cabeza, quieren fingir ahora que lo que vetan sin las licencias de "El as de bastos". Y si el texto de la respuesta, cuya copia he pedido, permite hacerlo (ya te lo diré), yo te sugeriría dar en La Novela Popular el cuento o nouvelle "El regreso", que pertenece a La cabeza del cordero, y que no dejaría de llamar la atención del lector amigo. Pero de esto volveré a escribirte cuando reciba la copia del documento que he pedido.

De todas maneras, he empezado (y tuve que suspender por razón de mi viaje a Méjico) una novela corta, que se titulará Vicente de la Roca, con destino a tu colección. Creo yo que, si desecho pronto una pequeña gripe que me aflige en estos días, la terminaré a tiempo de cumplir tu plazo. (...)

Hasta muy pronto. Te abraza cordialmente

Francisco Ayala.-

De hecho, también se cuenta con la carta posterior, en la que se confirma la denegación del permiso para publicar "el volumen de mis novelas cortas", aunque en realidad no le parece muy claro, confiesa, si se autoriza o deniega. Por ello, insistirá en que Cela publique el relato de "El regreso", porque, añade, "lo es de un exiliado", lo que llamará la atención pero no la de la censura, hasta tal punto es lúcido Ayala. No obstante, afirma que "Vicente de la Roca", dice, "va creciendo y tomando cuerpo", porque lleva la mitad escrita, y "terminará cumpliendo la infame hazaña a que está destinado". ¿Se refiere al héroe o al relato? Ya en la carta del 30 de diciembre de 1964 acepta la sugerencia del cambio de título, esto es, la modificación no es obra de Ayala. Falta la corrección de pruebas de esa "novelita", como ahora la llama. Incluso se hace eco del reciente estudio de K. Ellis, "que dará ganas a más de un lector español de enterarse de quién sea este viejo escritor compatriota suyo". Incluso insinúa que alguien reseñe ese estudio. También se refiere a Ricardo Gullón. Igualmente confiesa sus ganas de dar "una vuelta por ahí", en verano, esto es, por Londres, España y Milán. Termina diciendo: "Y encarga que, apenas salga El rapto, me lo manden, pues estoy muy deseoso de verle la cara a La Novela Popular". Incluso tenemos la carta de septiembre de 1965 dirigida a José María Ferrater Mora, justamente agradeciéndole la devolución de El rapto, donde confiesa algo en la línea de Ayala que revierte en el argumento también de esa obra: "Seguir narrando es lo que quiero y me gusta; pero la dificultad está, o a mí me lo parece, en captar lo significativo en un mundo tan evanescente como el que nos ha tocado en suerte. [...] ¡Felices los Balzac y los Galdós, cuyo problema era más bien si les alcanzarían los años de su vida para pergeñar toda la tela cortada que en su taller tenían!”. 


\section{Conclusión}

Así pues, a falta de continuar iluminando cuestiones estructurales, formales, temáticas e intertextuales en futuros trabajos, se ha de concluir volviendo a poner en valor el perfil de Ayala como escritor de novelas cortas, perspectiva que paradójicamente, como tal, no ha sido objeto de un estudio concreto y sobre el que se ha de seguir investigando. Ya que la delimitación de un corpus de novela corta tampoco resulta sencilla, también se ha de enfatizar las cuestiones históricas, sociológicas y editoriales, para leer e interpretar El rapto. Así se ha de reclamar esa faceta narrativa ayaliana con la que, además, continúa la herencia de Cervantes, de quien tanto aprendió, especialmente esa maestría original de fusionar géneros, discursos y campos literarios para crear un nuevo espacio imaginario. Una colección como La Novela Popular podría ser un medio, aunque discreto, para poder iniciar el regreso a su espacio, el de su país natal y el de su literatura. Por ello, asimismo, en futuros estudios se habrá de continuar profundizando en las motivaciones de este escritor que, como otros autores españoles en el exilio, escogió este género literario —con las vías editoriales que normalmente implica en ese período-, así como un modelo como el de Miguel de Cervantes - que a su vez asume otras fuentes clásicas y populares - para ofrecer otra literatura el lector que le es coetáneo. Por toda esa riqueza de lecturas Francisco Ayala no dejará de ser un escritor universal.

\section{Bibliografía}

AMORÓS, Andrés (1989): "Bibliografía básica de Francisco Ayala". Francisco Ayala: Premio Nacional de las Letras Españolas 1988. Madrid, Anthropos: 123-128.

AYALA, Francisco (1965a): El rapto. Madrid, Alfaguara (La Novela Popular Española, ${ }^{\circ}{ }^{0}$ ).

--- (1965b): Mis páginas mejores. Madrid, Gredos.

--- (1972): Confrontaciones. Barcelona, Seix Barral.

--- (1974): El rapto. Fragancia de jazmines. Diálogo entre el amor y un viejo. Ed. Estelle Irizarry. Barcelona, Labor.

--- (1978): La cabeza del cordero. Ed. Rosario Hiriart. Madrid, Cátedra.

--- (1993): El rapto. Madrid, Alfaguara.

--- (2007a) [1967]: "Nueva divagación sobre la novela". Estudios literarios. Obras Completas III. Barcelona, Círculo de Lectores/Galaxia Gutenberg: 163-177.

--- (2007b) [1970]: "Reflexiones sobre la estructura narrativa". Estudios literarios. Obras Completas III. Barcelona, Círculo de Lectores/Galaxia Gutenberg: 48-87.

--- (2007c) [2005]: “Cervantes y yo”. Estudios literarios. Obras Completas III. Barcelona, Círculo de Lectores/Galaxia Gutenberg: 1494-1497.

--- (2010) [1982]: “Regreso a Buenos Aires". Recuerdos y olvidos. Autobiografía(s). Obras Completas II. Barcelona, Círculo de Lectores/Galaxia Gutenberg: 354.

AZNAR, Manuel (ed.) (2016): Diccionario biobibliográfico: de los escritores, editores y revistas del exilio republicano de 1939. Sevilla, Renacimiento, 4 vols. 
BAQUERO GOYANES, Mariano: “Cervantes y Ayala: el arte del relato breve”. Cuadernos Hispanoamericanos 329-330 (1977): 311-326.

BLANES VALDEIGLESIAS, Carmen (2001): Un jardín "barroco" en los relatos de Francisco Ayala. Málaga, Universidad de Málaga.

CASAS, Ana (2007): El cuento español en la posguerra. Presencia del relato breve en las revistas literarias (1948-1969). Madrid, Mare Nostrum.

CAUDET, Francisco (1992): El exilio republicano en México: Las revistas literarias (19391971). Madrid, Fundación Banco Exterior.

CERVANTES, Miguel de (1981) [1976]: Novelas ejemplares. Ed. Mariano Baquero Goyanes. Madrid, Editoral Nacional.

CHICHARRO CHAMORRO, Antonio (1992): "Francisco Ayala, crítico y crítico de la crítica". Francisco Ayala, teórico y crítico literario: Actas del simposio celebrado en Granada, noviembre, 1991. Eds. Antonio Chicharro Chamorro y Antonio Sánchez Trigueros. Granada, Diputación de Granada: 253-264.

ELLIS, Keith: "Cervantes and Ayala's «El rapto»: the Art of Reworking a Story". Publications of the Modern Language Association of America LXXXIV/1 (1969): 1419. DOI: http://dx.doi.org/10.2307/1261152

ESCUDERO MARTÍNEZ, Carmen (1989): Cervantes en la narrativa de Francisco Ayala. Murcia, Universidad de Murcia.

FUNDACIÓN FRANCISCO AYALA: $\underline{\text { www.ffayala.es }}$

GARCÍA MONTORO, Adrián: "El rapto, novela ejemplar". La Torre. Revista de la Universidad de Puerto Rico 62 (1968): 151-165.

GRUIA, Ioana (2011): "La seducción del cuento: huellas cervantinas en «El rapto» de Francisco Ayala". De este mundo y los otros. Estudios sobre Francisco Ayala. Eds. Luis García Montero y Milena Rodríguez. Madrid, Visor: 331-340.

HIRIART, Rosario (1972): Las alusiones literarias en la obra narrativa de Francisco Ayala. Nueva York, Eliseo Torres \& Sons.

LOZANO MARCO, Miguel Ángel (2003): “Alonso Zamora Vicente en «La Novela Popular». Un balcón en la plaza". Con Alonso Zamora Vicente (Actas del Congreso Internacional "La lengua, la academia, lo popular, los clásicos, los contemporáneos) I. AA. VV. Alicante, Universidad de Alicante: 109-118.

MAGNIEN, Brigitte et al. (1986): Ideología y texto en El Cuento Semanal. Madrid, Ediciones de la Torre.

MARTÍNEZ ARNALDOS, Manuel (1975): La novela corta española en el primer tercio del siglo XX. Teoría y práctica. Murcia, Secretariado de Publicaciones e Intercambio Científico de la Universidad de Murcia.

PEDRAZA JIMÉNEZ, Felipe B. y Milagros RODRÍGUEZ CÁCERES (1996): Manual de literatura española. $3^{\mathrm{a}}$ ed. Tafalla, Cenlit.

PÉREZ BOWIE, José Antonio (2005): "La modernidad de la narrativa breve del exilio". Quimera 252 (dedicado a La narrativa breve del exilio republicano) (2005): 21-25.

POZUELO YVANCOS, José María (2015): “Ayala y el Quijote: lectura de El rapto”. De Re poética. Homenaje a D. Manuel Martínez Arnaldos. Eds. José M. a Pozuelo Yvancos, 
Abraham Esteve Serrano, Francisco Vicente Gómez y Carmen M. ${ }^{a}$ Pujante Segura. Murcia, Editum: 559-570.

PUJANTE SEGURA, Carmen M.a: "Notas para una recreación de la teoría sobre la novela corta española del siglo XX: A propósito de las escritoras en La Novela del Sábado (1953-1955)". Castilla. Estudios de Literatura 1 (2010): 38-59.

--- (2018): "La novela corta de los escritores españoles en el exilio”. En prensa.

RAMOS ORTEGA, Manuel J. (2010): Las alas de Ícaro: de poetas, revistas y exilios en la literatura española contemporánea. Madrid/Cáceres, Biblioteca Nueva/Servicio de Publicaciones de la Universidad de Extremadura.

RICHMOND, Carolyn (2011): "Raíces de la (re)creación: reflejos del exilio en Los usurpadores". De este mundo y los otros: Estudios sobre Francisco Ayala. Eds. Luis García Montero y Milena Rodríguez Gutiérrez. Visor, Madrid: 15-39.

SÁNCHEZ, Alberto (1966): “Cervantes y Francisco Ayala: original refundición de un cuento narrado en El Quijote”. Cuadernos Hispanoamericanos 196 (1966): 133-139.

SÁNCHEZ ÁLVAREZ-INSÚA, Alberto (1996): Bibliografía e historia de las colecciones literarias en España (1907-1957). Madrid, Asociación de Libros de Viejo.

SÁNCHEZ TRIGUEROS, Antonio y Manuel Ángel VÁZQUEZ-MEDEL (eds.) (2001): Francisco Ayala, escritor universal. Sevilla, Alfar.

SASTRE, Alfonso (1988): Los hombres y sus sombras. (Terrores y miserias del IV Reich). Murcia, Universidad de Murcia (ATE: Antología Teatral Española) (edición de Mariano de Paco).

SCHOLZ, László (2013): "La novela corta, ¿un género entre el cuento y la novela?". XV Encuentro de Latinoamericanistas Españoles. Noviembre 2012. AA. VV. Madrid, Trama: 1073-1079.

VALLES CALATRAVA, José Rafael (1992): "Cuento y novela en Francisco Ayala: similitudes y diferencias". Francisco Ayala, teórico y crítico literario: Actas del simposio celebrado en Granada, noviembre, 1991. Eds. Antonio Chicharro Chamorro y Antonio Sánchez Trigueros. Granada, Diputación de Granada: 379-390.

(C) Carmen M. ${ }^{\mathrm{a}}$ Pujante Segura

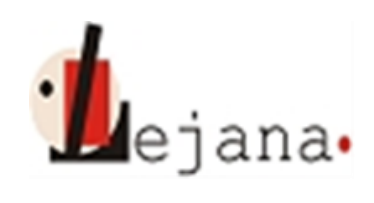

http://ojs.elte.hu/index.php/lejana

Universidad Eötvös Loránd, Departamento de Español, 1088 Budapest, Múzeum krt. 4/C 